\title{
Coral reveals ancient origins of human genes
}

\section{Carina Dennis, Sydney}

A study of coral suggests that ancient members of the animal kingdom slithered through the Precambrian mud with a hefty cache of genes in common with humans.

Surprisingly, many of these genes are not shared with creatures such as flies and worms, even though these animals evolved millions of years after coral. This calls into question some studies that use these model organisms to unravel the evolution of the human genome.

The investigation, published in this week's Current Biology (D. Kortschak et al. 13, 2190-2195; 2003), looked at some 1,300 gene sequences expressed in the coral Acropora millepora, and found that about 500 sequences had matches in gene databases. These sequences, called expressed sequence tags, represent either single genes, different pieces of the same gene, or expressed portions of DNA that do not contribute to a coding gene.

Of these, $90 \%$ were present in humans, and about $10 \%$ were found in humans but not in the fruitfly Drosophila melanogaster or the nematode worm Caenorhabditis elegans. This finding suggests that many genes thought to be vertebrate-specific may in fact have much older origins, and have been lost during the evolution of the fly and worm.

"The assumption was that coral would lack many of the genes found in higher animals," says Robert Saint of the Australian

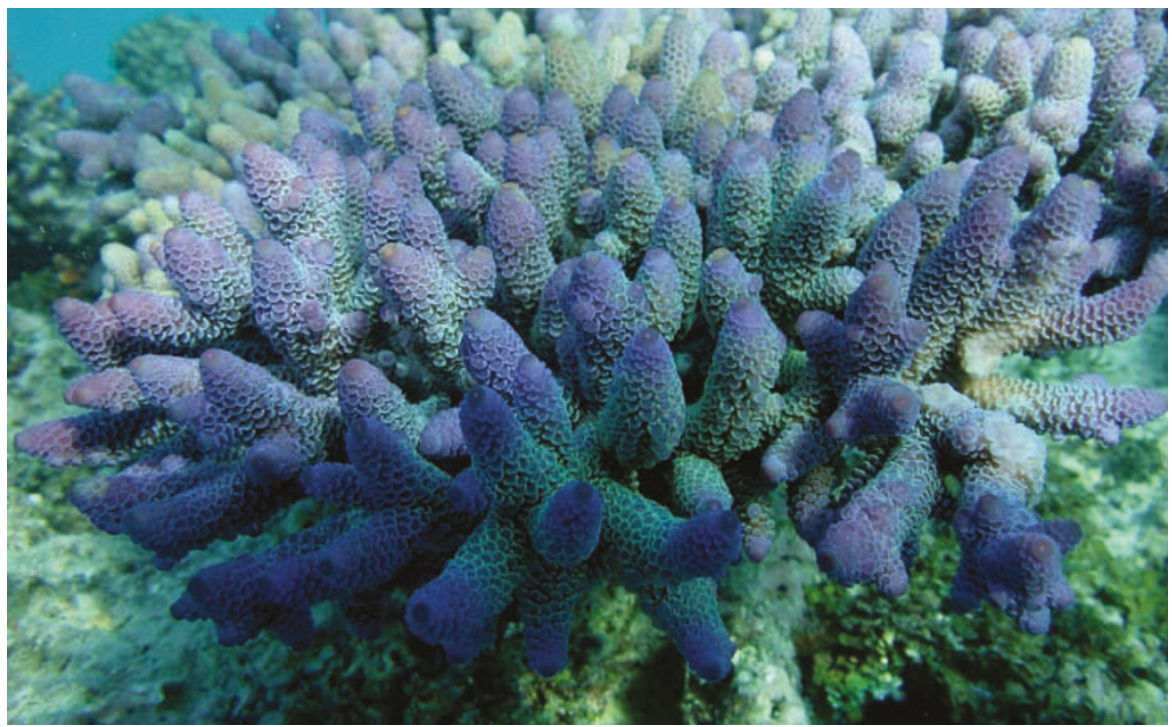

The coral Acropora millepora shares a surprisingly large number of genes with vertebrates.

\section{Elsevier waves goodbye to BioMedNet web portal}

\section{Jim Giles, London}

The popular life-sciences website BioMedNet is to close down for good. Observers say that the decision by scientific publisher Elsevier, which owns it, heralds a move away from general scientific websites, towards more specialized services.

Elsevier bought BioMedNet in 1997 from Vitek Tracz, an online-publishing pioneer who developed it for the London-based Current Science Group, which he chairs. BioMedNet evolved to bring together several Elsevier publications, such as the Trends series of journals, with conference reports, information on lab equipment, and access to the Medline database of life-sciences papers.

The website's 12 staff in London were told on 1 December that Elsevier was pulling the plug on BioMedNet, together with other general-purpose websites, including Chemweb and ElsevierEngineering.

"Having carefully reviewed the options available to us, we have decided that investments in the science and technology portals BioMedNet, Chemweb and ElsevierEngineering.com will be withdrawn," says a spokesperson for Elsevier.

When Elsevier bought BioMedNet, many experts anticipated that websites would soon generate substantial advertising revenue. "The web was hot," recalls Tracz. "People were full of expectation."

But David Worlock, chairman of Londonbased publishing consultancy EPS, says that Elsevier tested several different Internet business models, such as ScienceDirect, a website that provides access and search functions for Elsevier journals and reference
National University in Canberra, one of the study's authors. Instead, they were surprised to find genes similar to those that contribute to the specialized tissues of vertebrate nervous systems, even though coral has only a simple nerve net.

"There are important basic scientific questions that we need to ask using the coral system that should tell us about the evolution of developmental mechanisms in the animal kingdom," says David Miller, a molecular biologist at James Cook University in Townsville, Australia, and co-author of the study.

The idea that genes previously regarded as 'vertebrate innovations' may have evolved before vertebrates did isn't new. Alejandro Sánchez Alvarado, a developmental biologist at the University of Utah, previously found genes in the flatworm Schmidtea mediterranea that were thought to have evolved in vertebrates (A. S. Alvarado et al. Development 129, 5659-5665;2002).

But the idea that some animals may discard genes as they become more sophisticated is still controversial. "We won't really know until we have more worm and insect genomes to compare," says developmental biologist Eric Davidson of the California Institute of Technology in Pasadena.

The finding means that although fly and worm models are useful for studying gene function in development and cellular processes, they may be of limited value in studies of the evolution of human genes."We need to look at many other animal genomes that haven't undergone the same degree of gene loss to understand the evolution and function of human genes, and how they generate complexity," says Sánchez Alvarado. works, but has no other content of its own.

Worlock says that most scientists now go straight to journal articles using sites such as ScienceDirect, rather than via portal services such as BioMedNet. Elsevier is also locked in tough subscription negotiations with university libraries (see Nature 426, 217; 2003), sparking suspicions that revenue fears may have influenced their decision, he says.

Elsevier is expected to focus its Internet efforts on sophisticated search tools to complement ScienceDirect. The company is said to be developing an application known as Scopus, which will allow users to probe the network of citations that link related papers. Such a service would be a rival for ISI Web of Science, a tool marketed by Philadelphia-based Thomson ISI. www.bmn.com 